AperTO - Archivio Istituzionale Open Access dell'Università di Torino

Awareness of Gender Medicine among family doctors. A field investigation

This is a pre print version of the following article:

Original Citation:

Availability:

This version is available http://hdl.handle.net/2318/1734882

since 2020-04-02T13:01:32Z

Published version:

DOI:10.1080/10852352.2019.1624354

Terms of use:

Open Access

Anyone can freely access the full text of works made available as "Open Access". Works made available under a Creative Commons license can be used according to the terms and conditions of said license. Use of all other works requires consent of the right holder (author or publisher) if not exempted from copyright protection by the applicable law. 


\section{Awareness of Gender Medicine among family doctors. A field investigation}

Silvia Gattino*, Norma De Piccoli*, Mariasusetta Grosso**,*** Simonetta Miozzo****, Gabriella Tanturri***, and Chiara Rollero*

*Department of Psychology, University of Turin, Turin, Italy

**Organization of Basic Health Services, Turin, Italy

***Italian Women's Medical Association, Section of Turin, Italy

****Local Healthcare Services, Collegno and Pinerolo (Turin), Italy; and Italian Society of General Medicine and Primary Care, Section of Turin, Italy

Ample evidence has shown that gender is one of the key determinants of health and illness and that a better understanding of gender-specific determinants can contribute to greater equity and equality in health services, with better health for both women and men. Nonetheless, the androcentric bias prevalent in healthcare makes it difficult to address the needs of either women or men adequately. Strengthening research into gender medicine issues is therefore desirable.

With the present study we investigated awareness of gender medicine among practicing primary care physicians and doctors-in-training in primary care and whether sexism affects awareness of gender medicine. Our findings show that there is a need for training programs to enhance gender awareness among both practicing physicians and those in training. Implications for policies are discussed.

Keywords: health, Gender Medicine, gender awareness 


\section{Introduction}

\section{Health from gender perspective}

The need to view health in a gender perspective has an empirical base in epidemiological data. Around the mid-1980s studies began to show a difference in morbidity and mortality rates between men and women: while women were more often affected by illness, their life expectancy was longer than for men (Moore, 2010). Several years followed before a scientific explanation for this difference would be forthcoming. What explanations and hypotheses are offered for interpreting it?

Klinge and Bosch (2005) state that women and men differ in the nature and course of illness and in their vulnerability to specific illnesses, be it through genetic causes (e.g., sex-linked conditions, genetic mutations, inheritance patterns of genetic coding or polymorphisms) or environmental exposure (e.g., workplace hazards, bacterial exposure, nutrition, violence, poverty, lifestyle) or a combination of the two (epigenetic regulation, with silent genes switched on by the environment). More complex theoretical models go beyond the perspective on genetic and biological elements to focus on the interplay between biological and social factors. Denton and colleagues (2004) observed that psychophysical wellbeing seems to be affected by socio-economical aspects (i.e., educational level, economic status, occupation), behavioral determinants (i.e., actions that influence health, including physical activity, smoking, and obesity), and psychosocial dimensions (i.e., psychological resources and stressors) (Rollero, 2014). Moreover, as compared to men, women have less access to positive material and social conditions that favor wellbeing and health. They are less likely to be employed, more likely to have lower income, be devoted to domestic labor, and be caregivers. They also show lower levels of self-esteem and control. Unsurprisingly, the protective effect of social support is more relevant for women than for men (De Piccoli, Ceccarini, Gattino, \& Rollero, 2016; Rollero, Gattino, \& De Piccoli, 2014).

Differential socialization to gender roles fosters different behaviors and reactions to health problems in men and women. For instance, seeking and asking for help are competencies more typically used by women. Verdonk and colleagues (2008) noted that not only do psychological gender differences in health and illness exist in help-seeking behavior, consequences of and coping with disease, and symptom perception, but also that socially constructed gender differences determine whether men and women can realize their health potential, given that social norms regarding risk-taking differentially affect men and women. Moreover, gender also affects doctor-patient communication, influencing how 
patients describe their symptoms and how doctors interpret patients' reporting of symptoms and complaints: self-report of symptoms in men are more likely to be interpreted as organic but those in women as psychosocial. That female patients are less often considered for referral or further diagnostic investigation than men with similar symptoms raises questions of unequal care and gender bias (Andersson, Verdonk, Johansson, Lagro-Janssen, \& Hamberg, 2012).

This can give rise to disparities in healthcare and to gender bias, resulting in unequal access to treatment for similar symptom (Andersson et al., 2012). With regard to the differences in the ways men and women report their health status or illness, women are noted to mention their social context more often than men, whereas men tend to refer to their body as a kind of machine. Such differences in communicative style can influence doctors' perception of their patients' problems, overestimating the social or relational aspects of women's reports while underestimating their impact, including also mental health problems, in male patients. A widely held belief is that communication is easier with hospitalized male than female patients (Verdonk, Benschop, de Haes, \& Lagro-Janssen, 2009; for further detail see also Andersson et al., 2012; Verdonk et al., 2008). Moreover, research has shown that treatment for the same condition differs between female and male patients (Andersson et al., 2012; see also Verdonk et al., 2008; Verdonk et al., 2009 for further details).

Hawkes and Buse (2013) have pointed out that "gender - a social construct - has a substantial effect on health behaviours, access to health care, and health system responses. Gender norms, whether perpetuated by individuals, communities, commercial interests or underpinned by legislation and policy, contribute to disparities in the burden of ill health on men and women" (p. 1785). The tendency to underestimate or not take the role of gender properly into account has led to a lack of considering the evidence for the determinants of gender that influence health and illness in men and women. Hawkes and Buse (2013) go on to state that progress in the desired direction would disaggregate gender or sex in global research on health in reference to interventions, monitoring, and evaluation. It would also implicate the recognition of the gender norms that influence health and the awareness that gender is a political issue since specific interests perpetuate gender norms and explicate the strategies underlying these interests.

\section{Gender Medicine: a scientific, psychosocial, and ethical question}


Feminist health movements of the late 1960s began to address inequalities in women's healthcare (Moore, 2010). Despite the progress achieved in gender equality in healthcare research, knowledge, and policy (Doyal, 2001; Phillips, 2005; Risberg, Johansson, Westman, \& Hamberg, 2003), gender bias and inequality persist in medicine (Bierman, 2007; Colella et al., 2015; Hamberg and Larsson, 2009; Kent, Patel, \& Varela, 2012). While women's underrepresentation in medical research has resulted in limited and inaccurate knowledge about female health (Hamberg, 2008), the production and maintenance of gender stereotypes in clinical medicine affects medical diagnosis, treatment, and patient management (Balsa \& McGuire, 2003; Martin \& Suls, 2003). In the late 1980s, these issues were taken up also by women's health studies developed mainly in the Netherlands that underline:

- The neglect of gender within medicine, as knowledge about health and illness is based on the male as prototype (Metoyer \& Rust, 2011; Parker, Larkin \& Cockburn, 2017)

- The need to redefine the concept of illness as a biomedical dimension, which becomes meaningful in specific individual and social life circumstances (Lagro-Janssen, 2007).

Human and animal pharmacological studies have been primarily conducted on males, assuming that the symptoms, prognosis, and course of disease in males are paradigmatic and not gender-specific. Contemporary studies are demonstrating, however, that, because diseases manifest differently in men and women, prevention, diagnosis, and treatment should be gender-specific. Research into the biological differences between men and women is a growing field of enquiry, but the risk is that its scope may be limited to such differences. By contrast, a wide array of research lines may embrace a perspective of gender medicine, which implies that life's conditions, an individual's societal position and society's expectations of being male or female concur together with biological and psychological factors to determine one's health. An objective of the Commission on Social Determinants of Health (World Health Organization, Commission on Social Determinants of Health, 2008) is to extend the knowledge base, including the development of research to address gender bias. Indeed, mechanisms and policies need to be developed to ensure that gender biases in both the content and processes of health research are avoided and corrected (World Health Organization, 2007). These mechanisms and policies should: (a) include women in clinical trials and other health studies in appropriate numbers, and analyze the data generated from clinical trials and other health studies using gender-sensitive tools and methods; (b) strengthen women's role in health research by redressing gender imbalances in research (World Health Organization, Commission on Social Determinants of Health, 2008). 
Research into the role that gender plays in health has focused on gender awareness among physicians and / or medical students and developed scales to measure this dimension (Andersson et al., 2012; Salgado, Vogt, King, \& King, 2002; Verdonk et al., 2008). Specifically, Verdonk and colleagues (2008) developed a tool to detect the affective components of gender awareness, i.e., gender sensitivity (GS) and gender-role ideology towards patients (GRI-P) and doctors (GRI-D). They stated that "in gender-sensitive health care, the emphasis is on specific characteristics, life events, and experiences (...) that belong to one of the genders more than to the other gender." (p. 224). In the healthcare context, "gender sensitivity means that physicians are sympathetic towards addressing gender issues, while taking care to avoid stereotyped generalizations" (Verdonk et al., 2008, p. 224). Gender-role ideology, instead, depicts a healthcare worker's attitude towards male and female patients and doctors. As Verdonk et al. (2008) point out, "the selection and socialization process of physicians does not completely erase the effects of gender-role ideology and gender stereotypes about men and women in the doctor-patient interaction" (p. 224).

Research into the psychological dimensions of such processes is still scarce, as are studies on the context and the professional role (e.g., practicing physicians versus medical students). The overall aim of the present study was to determine awareness of the gender dimension among primary care physicians and doctors-in- training.

\section{Current Study}

Our study had two specific aims. The first was to assess the level of gender awareness and sexism in a sample of practicing primary care providers and doctors-in-training as primary care physicians. This particular population sample was chosen for two reasons. First, because primary care physicians are the first healthcare providers people turn to for medical problems, we wanted to determine the level of awareness of gender-oriented medicine and to what extent gender stereotypes are maintained by general practitioners. Second, we wanted to avoid comparing participants from different medical

specialties. Cardiology, albeit with country-by-country differences, was among the first specialties to address the need for gender analysis of clinical aspects. The second aim of this study was to determine whether this association varies according to the respondent's gender by evaluating the association among professional roles, sexism, and gender awareness. Professional role and sexism were examined as independent variables and gender awareness as an outcome measure. 
Since courses on gender medicine are a recent addition to professional education and are mainly addressed to doctors-in-training, we expected that the role would differentiate the gender sensitivity, i.e., that both male and female doctors-in-training would be more aware than practicing primary care physicians of gender medicine. Conversely, for gender-role ideology (GRI-P and GRI-D), we did not expect any differences between practicing physicians and doctors-in-training because while training is an important step to develop gender sensitivity in medicine, it is necessary but not sufficient to overcome gender stereotypes that affect the role of ideology towards patients and doctors. Here, we refer to a specific form of gender-related prejudice, the ambivalent sexism and the ambivalent attitudes towards men (see Glick \& Fiske, 1997; 1999).

To our knowledge, no studies to date have analysed the perception and representation of gender medicine in a sample of primary care physicians. Since the present study is the first attempt to explore this issue and the role of sexism and professional role in gender awareness, the available literature does not allow to formulate a hypothesis about the role of the different forms of sexism (ambivalent and hostile). In general, we can expect that hostile sexism (towards women and men) could be related to higher gender-role ideology (towards both patients and physicians).

\section{Method}

\section{Participants}

The total sample consisted of 431 (44.5\% women) Italian physicians (age range 27-72 years, $M=50$; $S D=13.5): 311(41.2 \%$ women) were primary care physicians (age range 30-72 years, $M=58 ; S D=$ 6.7) and 120 (53\% women) were doctors-in-training for primary care (age range 27-54 years, $M=31$; $S D=4.1)$. The two groups differed by gender $\left(\chi^{2}(1)=4.75 ; \mathrm{p}=.02\right)$. This finding is consistent with the national situation, where women make up $63 \%$ of physicians between 24 and 39 years of age. Only $24 \%$ had participated in table round discussions, seminars, or training activities about gender medicine (20.4\% of primary care physicians; $4 \%$ of doctors-in-training).

\section{Procedure and measures}

The Ethics Committee of Turin University approved the study protocol. Data were collected by the researchers themselves and by research assistants trained by the researchers. The data were gleaned from a structured, self-report, pencil-and-paper questionnaire that took about 20 minutes to complete. The primary care physicians were contacted before the beginning of periodic team meetings via a 
convenience sampling method; the doctors-in-training were contacted before the beginning of training via a convenience sampling method. The questionnaire was completed in the presence of the researcher, who collected it immediately after compilation. Although this sampling technique has the limitation that it is not purely random, every effort was made to access a wide range of respondent demographics, including age and gender. Participation in the study was voluntary and the respondent's anonymity was ensured in all phases of data collection and analysis. We used validated scales, when available, and translated and back translated scales for the other measures. The following variables were investigated:

Gender Awareness was measured using the Nijmegen Gender Awareness in Medicine Scale (NGAMS; Verdonk et al., 2008) on three subscales: Gender Sensitivity, Gender Role Ideology towards Patients, and Gender Role Ideology towards Doctors. The Gender Sensitivity (14 items) subscale assesses the degree to which doctors are sensitive to dealing with gender issues (e.g., "Physician's knowledge of gender differences in illness and health increase quality of care"; "Addressing differences between men and women creates inequity in health care", reverse coded). Response options range from 1 (strongly disagree) to 5 (strongly agree). Items were reversed when needed so that higher averaged scores indicated higher sensitivity towards gender issues in medicine. The measure demonstrated good internal consistency $(\alpha=.85)$. The Gender Role Ideology towards Patients (GRI-P, 11 items) and towards Doctors (GRI-D, 7 items) evaluate the care that doctors take to avoid stereotyped generalizations towards, respectively, patients and physicians. For example: "Male patients better understand the approach of physicians than female patients"; "Female patients compared to male patients have unreasonable expectations of physicians"; "Male physicians put too much emphasis on technical aspects of medicine compared to female physicians; "Female physicians extend their consultations too much compared to male physicians". Response options range from 1 (strongly disagree) to 5 (strongly agree), where higher average scores correspond to a higher level of agreement on gender stereotypes. Both measures demonstrated good internal consistency (GRI-P, $\alpha=.88$; GRI-D, $\alpha=.78)$.

Ambivalent Sexism. Glick and Fiske's short version of the Ambivalent Sexism Inventory (ASI, 1996) and the Ambivalence Toward Men Inventory (AMI, 1999) assess sexist attitudes. These measures have been validated in the Italian context (Rollero, Glick, \& Tartaglia, 2014) leading to the Italian versions of the ASI AMI consisting of 12 items: six assess benevolent sexism (BS; BM) and six hostile sexism (HS; HM): e.g., "Many women have a quality of purity that few men possess" (ASI-B); "Women seek 
to gain power by getting control over men needs" (ASI-H); "Even if both members of a couple work, the woman ought to be more attentive to taking care of her man at home" (AMI-B), "When men act to 'help' women, they are often trying to prove they are better than women" (AMI-H). Items were rated on 6-point Likert-type scale, ranging from 0 (strongly disagree) to 5 (strongly agree), where higher scores indicate a greater sexist attitude. Alphas for ASI-B and ASI-H were .78 and .85, respectively. Alphas for AMI-B and AMI-H were .81 and .80, respectively.

Sociodemographic information. On completion of the questionnaire, the participants were asked to provide socio-demographic information (gender, age, number of years practicing medicine, participation in congresses, workshops or seminars on gender differences in medicine).

\section{Data Analyses}

To evaluate the relationship between professional role, sexism, and gender awareness in medicine, we performed a multivariate hierarchical regression analysis, replicated for each gender sample on each of

the three gender awareness subscales (i.e., gender sensitivity, gender role ideology towards patients and towards doctors). The three models included five predictors of gender awareness, logically organized into two blocks of content: (a) professional role; (b) ambivalent sexism. The two sets of variables were entered into the model following the above-mentioned order. The variance inflation factor (VIF) was used to evaluate the presence of multicollinearity using a cut-off of 2.5 . $\mathrm{R}^{2}$ statistics was used to assess model fit. All statistical analyses were carried out using IBM-SPSS Statistics version 24.0 software.

\section{Results}

\section{Descriptive Analyses}

Table 1 presents the average scores, the standard deviations, and the correlations among Gender Awareness and Ambivalent Sexism subscales separately by gender. Overall, a higher score was noted for the women on the GS subscale $[\mathrm{t}(397)=2.86, \mathrm{p}<.005]$. Conversely, the ASI-B score was higher for the men $[\mathrm{t}(399)=-2.37, \mathrm{p}<.05$, ASI-H $\mathrm{t}(409)=-4.56, \mathrm{p}<.001]$ and AMI-B $[\mathrm{t}(410)=-4.02, \mathrm{p}<.001]$. In both samples, GS was negatively correlated with GRI-P, whereas this subscale was negatively correlated also with GRI-D, ASI-H, and AMI-B only in the men's sample. In both samples, the subscale assessing gender role ideology towards doctors (GRI-D) was positively correlated with GRI-P and the four subscales of ambivalent sexism. GRI-P was positively correlated with the four subscales of 
ambivalent sexism in the men's sample, but it did not correlate with ASI-B in the women's sample. In both samples, all ambivalent sexism subscales were positively correlated with themselves.

Table 1. Descriptive Statistics and Intercorrelations between Gender Awareness and Ambivalent Sexism Subscales.

\begin{tabular}{|c|c|c|c|c|c|c|c|c|}
\hline \multicolumn{2}{|l|}{ Gender } & \multirow{2}{*}{$\begin{array}{c}1 \\
1\end{array}$} & \multirow[t]{2}{*}{2} & \multirow[t]{2}{*}{3} & \multirow[t]{2}{*}{4} & \multirow[t]{2}{*}{5} & \multirow[t]{2}{*}{6} & \multirow[t]{2}{*}{7} \\
\hline Women & 1. GS & & & & & & & \\
\hline & 2 GRIP & $-.26 * *$ & 1 & & & & & \\
\hline & 3. GRID & -.08 & $.59 * *$ & 1 & & & & \\
\hline & 4. ASI-B & .13 & .04 & $.23 * *$ & 1 & & & \\
\hline & 5. ASI-H & -.05 & $.38 * *$ & $.39 * *$ & $.40 * *$ & 1 & & \\
\hline & 6. AMI-B & -.07 & $.26 * *$ & $.40 * *$ & $.56 * *$ & $.67 * *$ & 1 & \\
\hline & 7. AMI-H & .02 & $.29 * *$ & $.27 * *$ & $.42 * *$ & $.45 * *$ & $.46 * *$ & 1 \\
\hline & Mean & 3.93 & 2.26 & 2.03 & 1.59 & 1.42 & 1.35 & 2.34 \\
\hline & $S D$ & .66 & .78 & .64 & 1.07 & 1.10 & 1.02 & 1.14 \\
\hline \multirow[t]{9}{*}{ Men } & 1. GS & 1 & & & & & & \\
\hline & 2 GRIP & $-.26 * *$ & 1 & & & & & \\
\hline & 3. GRID & $-.20 * *$ & $.60 * *$ & 1 & & & & \\
\hline & 4. ASI-B & .06 & $.20 * *$ & $.23 * *$ & 1 & & & \\
\hline & 5. ASI-H & $-.22 * *$ & $.54 * *$ & $.42 * *$ & $.29 * *$ & 1 & & \\
\hline & 6. AMI-B & $-.28 * *$ & $.46 * *$ & $.41 * *$ & $.36 * *$ & $.74 * *$ & 1 & \\
\hline & 7. AMI-H & .02 & $.27 * *$ & $.28 * *$ & $.41 * *$ & $.31 * *$ & $.42 * *$ & 1 \\
\hline & Mean & 3.72 & 2.38 & 2.05 & 1.86 & 1.95 & 1.78 & 2.18 \\
\hline & $S D$ & .79 & .82 & .77 & 1.15 & 1.22 & 1.16 & 1.08 \\
\hline
\end{tabular}

$* \mathrm{p}<.05 . * * \mathrm{p}<.01$

\section{Regression Models}

The regression models showed a better model fit for the data from the male respondents (Tables 2, 3, and 4). In terms of $\mathrm{R}^{2}$, the best fit for the models was obtained for the GRI-P subscale, while the fit was less satisfactory for GS (Table 2). In the women's sample, the only significant predictor of GS was the 
professional role (being a doctor-in-training was positively associated with this dimension of gender awareness). In the men's sample, being a doctor-in-training and benevolent sexism toward women were positively associated with GS. Conversely, benevolent sexism toward men was negatively associated with this subscale. In both samples, the only predictors that were significantly associated with GRI-P and GRI-D were the subscales of ambivalent sexism. Specifically, in the women's sample, a higher level of ASI-H and AMI-H were positively related to GRI-P, whereas a higher level of ASI-B was negatively associated with it (Table 3). On the GRI-D subscale, higher levels of ASI-H and AMI-B were positively related to it. In the men's sample, the only significant predictor on both subscales, GRI$\mathrm{P}$ and GRI-D, was ASI-H, which was positively associated with these two dimensions of gender awareness.

Table 2. Hierarchical Multiple Linear Regression Models Predicting GS.

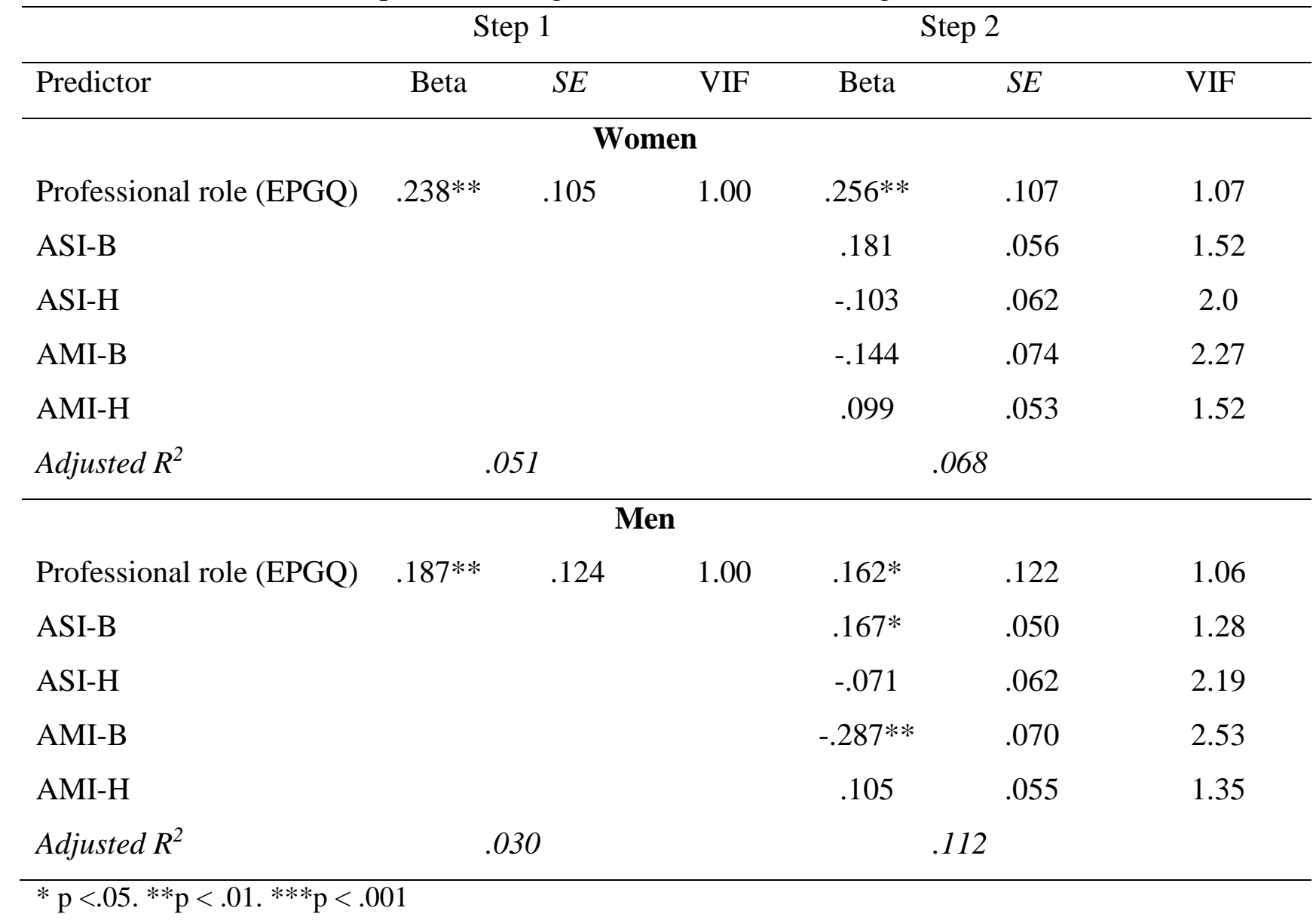


Table 3. Hierarchical Multiple Linear Regression Models Predicting GRI-P.

\begin{tabular}{|c|c|c|c|c|c|c|}
\hline & \multicolumn{2}{|c|}{ Step 1} & \multicolumn{4}{|c|}{ Step 2} \\
\hline Predictor & Beta & $S E$ & VIF & Beta & $S E$ & VIF \\
\hline \multicolumn{7}{|c|}{ Women } \\
\hline Professional role (EPGQ) & -.096 & .127 & 1.00 & -.115 & .119 & 1.07 \\
\hline ASI-B & & & & $-.210 *$ & .063 & 1.56 \\
\hline ASI-H & & & & $.335^{* *}$ & .068 & 1.93 \\
\hline AMI-B & & & & -.14 & .07 & 2.27 \\
\hline AMI-H & & & & $.063 *$ & .080 & 1.49 \\
\hline Adjusted $R^{2}$ & \multicolumn{3}{|c|}{.003} & \multicolumn{2}{|c|}{.185} & \\
\hline \multicolumn{7}{|c|}{ Men } \\
\hline Professional role (EPGQ) & -.101 & .131 & 1.00 & -.014 & .115 & 1.06 \\
\hline ASI-B & & & & .002 & .05 & 1.30 \\
\hline ASI-H & & & & $.413 * * *$ & .058 & 2.20 \\
\hline AMI-B & & & & .098 & .066 & 2.51 \\
\hline AMI-H & & & & .109 & .051 & 1.35 \\
\hline Adjusted $R^{2}$ & \multicolumn{3}{|c|}{.005} & \multicolumn{2}{|c|}{.274} & \\
\hline
\end{tabular}

$* \mathrm{p}<.05 . * * \mathrm{p}<.01 . * * * \mathrm{p}<.001$

Table 4. Hierarchical Multiple Linear Regression Models Predicting GRI-D.

\begin{tabular}{lcccccc}
\hline \multicolumn{7}{c}{ Step 1 } \\
\hline Predictor & Beta & SE & VIF & Beta & SE & VIF \\
\hline & \multicolumn{7}{c}{ Women } \\
Professional role (EPGQ) & -.036 & .104 & 1.00 & -.081 & .097 & 1.06 \\
ASI-B & & & & -.014 & .052 & 1.55 \\
ASI-H & & & $.207^{*}$ & .056 & 1.94 \\
AMI-B & & & $.260^{*}$ & .066 & 2.22 \\
AMI-H & & & .063 & .048 & 1.48 \\
Adjusted $R^{2}$ & & & & .182 &
\end{tabular}

\section{Men}

$\begin{array}{lllllll}\text { Professional role (EPGQ) } & -.037 & .122 & 1.00 & .051 & .111 & 1.06\end{array}$ 
ASI-B

ASI-H

AMI-B

AMI-H

.126

.051

Adjusted $R^{2}$

$-.003$

.203

$* \mathrm{p}<.05 . * * \mathrm{p}<.01 . * * * \mathrm{p}<.001$

\section{Conclusions}

With this study we wanted to assess the level of gender awareness in medicine in a sample of Italian primary care physicians and doctors-in-training for primary care and to determine whether gender stereotype, i.e., ambivalent sexism, is associated with gender awareness. In general, the mean GS scores exceeded the midpoint of the scale, whereas the mean GRI-P, GRI-D, and the four forms of ambivalent sexism scores were under the midpoint of the scales for both the women's and men's samples. Nevertheless, a higher score on the GS subscale was noted for the women, indicating their greater sensitivity to dealing with gender issues than their male colleagues. As more and more women are entering the medical profession in Italy, there is reason for optimism in seeing a change in this direction. Conversely, the men scored higher on the ASI-B, ASI-H, and AMI-B scales. Gender sensitivity was observed to be higher for the doctors-in-training than the practicing primary care providers, whereas the GRI-P was higher for the latter group.

In general, these patterns of influence highlight a significant contribution of the professional role to awareness of gender sensitivity: both male and female doctors-in-training were noted to be more sensitive to taking gender differences into account in practicing their profession. Our findings suggest a cultural change: the younger doctors seemed to be more aware of gender medicine. In Italy, where courses devoted to gender medicine are offered at only one university, postgraduate medical education has just begun to raise awareness among young physicians of gender differences in medicine. Our data show that sexism was a significant predictor of gender sensitivity only for the male sample: ASI-B was positively associated with GS, whereas AMI-B was negatively associated with this dimension. Because benevolent sexism confirms the status quo about gender differences, but is based on a positive trait, it confirms a sexist ideology while offering, at the same time, a form of paternalistic protection to the weaker group (i.e., women). Paradoxically, the benevolent sexism towards women could be "functional" to develop a gender medicine that reinforces the so-called "women are wonderful 
effect" (see, Eagly and Mladinic, 1989; 1994). Moreover, Glick et al. (2004) found that stereotypical traits associated with women are evaluated more positive than those associated with men. In both samples the ASI-H was a significant predictor of the ideology of gender roles towards both patients and doctors. In the women's sample, ASI-B was negatively associated with GRI-P (i.e., low benevolent sexism towards women affects the female physicians, a stereotypical ideology towards patients), whereas AMI-H was positively associated with this ideology of gender roles and the AMI-B was a predictor of GRI-D. These data are interesting when taken as a whole: ASI-H was positively associated with stereotypical attitudes towards both physicians and patients similarly for the men and the women. However, while this was the only form of sexism affecting GRI-P and GRI-D for the men, AMI-B was associated with stereotypes towards doctors for the women. According to Fiske and colleagues (2002), positive stereotypes do not contrast prejudice, but rather are functionally congruous with derogatory stereotypes on the other sphere. Indeed, although more and more women are practicing medicine today than in the past, medical power remains stereotypically male. Because male physicians make up a powerful group, female physicians expressing benevolent stereotypes towards men tend to hold a stereotypical generalization towards physicians.

This preliminary study contributes to advancing our knowledge about the level of gender awareness in medicine and the role ambivalent sexism plays in affecting it. Our findings highlight the need for cultural and scientific change toward the development of gender health. These strengths notwithstanding, we acknowledge some limitations. First, our data refer to the cultural context of northern Italy, and therefore cannot be generalized to other countries and cultures and require caution in their interpretation. It would be desirable to extend research to include comparison across other occupational categories (e.g., nurses) and cultural contexts. Cross-comparison might allow to reveal whether innovative political policies are successful in removing gender stereotypes. In Italy, though progress is slow, more and more initiatives are promoting greater awareness of gender medicine and health.

Healthcare workers need to be trained in good communication and listening skills, how to tailor their communication to meet their patients' needs (Kickbusch, Wait, \& Maag, 2006), and to be aware of how gender influences health outcomes and health-seeking behaviors. To achieve this objective, gender must become part of the training curriculum on the social determinants of health (World Health Organization, Commission on Social Determinants of Health, 2008). 
Since "gender inequalities, discrimination, and gender stereotypes are important underlying factors influencing behaviour and practices that affect women's health across the life-course" (World Health Organization, 2016, p. VI) "health systems should respond to women's health needs and promote gender equity. (...) Because, according to the values of Health 2020, gender is a determinant of health alongside social and environmental determinants; moreover gender mainstreaming is a mechanism to achieve better, more equitable and sustainable health for both men and women in the European Region" (World Health Organization, 2016, p. VII). 


\section{References}

Andersson, J., Verdonk, P., Johansson, E.E., Lagro-Janssen, T., \& Hamberg, K. (2012). Comparing gender awareness in Dutch and Swedish first-year medical students - results from a questionnaire, BMC Medical Education, 12(3), 1-10. doi:10.1186/1472-6920-12-3.

Balsa, A. I., \& McGuire, T. G. (2003). Prejudice, clinical uncertainty and stereotyping as sources of health disparities. Journal of Health Economics, 22(1), 89-116. doi: 10.1016/S0167-6296(02)00098-X.

Bierman, A. S. (2007). Sex matters: gender disparities in quality and outcomes of care. Canadian Medical Association Journal, 177(12), 1520-1521.doi:10.1503/cmaj.071541.

Colella, T. J. F., Gravely, S., Marzolini, S., Grace, S.L., Francis, J.A., Oh, P., \& Scott, L.B. (2015). Sex bias in referral of women to outpatient cardiac rehabilitation? A meta-analysis. European Journal of Preventive Cardiology, 22(4), 423-441. doi: 10.1177/2047487314520783.

Denton, M., Prus, S., \& Walters, V. (2004). Gender Differences in Health: A Canadian Study of the Psychosocial, Structural and Behavioural Determinants of Helath, Social Science \& Medicine, 58(2), 2585-2600. doi: 10.1016/j.socscimed.2003.09.008.

De Piccoli, N., Ceccarini, L., Gattino, S., \& Rollero, C. (2016). Health and Social Support from a Gender Perspective. In C. Castillo (Ed.), Social Support: Gender Differences, Psychological Importance and Impacts on Well-Being, NY: Nova Publisher.

Doyal, L. (2001). Sex, gender, and health: the need for a new approach. British Medical Journal, 323(7320), 1061-1063. doi:10.1136/bmj.323.7320.1061.

Eagly, A. H., \& Mladinic, A. (1989). Gender stereotypes and attitudes toward women and men. Personality and Social Psychology Bulletin,15(4), 543-558. doi: 10.1177/0146167289154008.

Eagly, A. H., \& Mladinic, A. (1994). Are People Prejudiced Against Women? Some answers from research on attitudes, gender stereotypes, and judgments of competence. European Review of Social Psychology, 5(1), 1-35. doi: 10.1080/14792779543000002.

Fiske, S. T., Cuddy, A. J. C., Glick, P., \& Xu, J. (2002). A model of (often mixed) stereotype content: Competence and warmth respectively follow from perceived status and competition. Journal of Personality and Social Psychology, 82(6), 878-902. doi: 10.1037/0022-3514.82.6.878.

Glick, P., \& Fiske, S. T. (1997). Hostile and benevolent sexism: Measuring ambivalent sexist attitudes toward women. Psychology of Women Quarterly, 21(1), 119-135. doi: 10.1111/j.14716402.1997.tb00104.x. 
Glick, P., \& Fiske, S. T. (1999). The Ambivalence toward Men Inventory: Differentiating hostile and benevolent beliefs about men. Psychology of Women Quarterly, 23(3), 519-536. doi: 10.1111/j.14716402.1999.tb00379.x.

Glick, P., Lameiras, M., Fiske, S. T., Eckes, T., Masser, B., Volpato, C., ... Wells, R. (2004). Bad but bold: Ambivalent attitudes toward men predict gender inequality in 16 nations. Journal of Personality and Social Psychology, 86(5), 713-728. doi:10.1037/0022-3514.86.5.713.

Hamberg, K. (2008). Gender Bias in Medicine. Women's Health, 4(3), 237-243. doi: 10.2217/17455057.4.3.237.

Hawkes, S., \& Buse, K. (2013). Gender and global health: evidence, policy, and inconvenient truths. Lancet, 381(9879), 1783-1787. doi:10.1016/S0140-6736(13)60253-6.

Kent, J. A., Patel, V., \& Varela, N. A. (2012). Gender Disparities in Health Care. Mount Sinai Journal of Medicine: A Journal of Translational and Personalized Medicine, 79(5), 555-559. doi: $10.1002 / \mathrm{msj} .21336$.

Kickbusch, I., Wait, S., \& Maag, D. (2006). Navigating health: The role of health literacy. Alliance for health and the future, International Longevity Centre-UK. Retrieved from http://www.ilcuk.org.uk/files/pdf_pdf_3.pdf

Klinge, I., \& Bosch, M. (2005). Transforming Research Methodologies in EU Life Sciences and Biomedicine: Gender-Sensitive Ways of Doing Research, European Journal of Women's Studies, 12(3), 377-395. doi: 10.1177/1350506805054276.

Lagro-Janssen, T. (2007). Sex, Gender and Health: Developments in Research. European Journal of Women's Studies, 14(1), 9-20. doi: 10.1177/1350506807072314.

Martin, R. \& Suls, J. (2003). How gender stereotypes influence self-regulation of cardiac health careseeking and adaptation. In: L.D. Cameron \& H. Leventhal (Eds.), The Self-regulation of Health and Illness Behaviour (pp. 220-241). New York: Routledge.

Metoyer, A. B., \& Rust, R. (2011). The egg, sperm, and beyond: gendered assumptions in gynecology textbooks. Women's studies, 40(2), 177-205. doi: 10.1080/00497878.2011.537986.

Moore, S.E.H. (2010). Is the Healthy Body Gendered? Toward a Feminist Critique of the New Paradigm of Health, Body \& Society, 16(2), 95-118. doi: 10.1177/1357034X10364765.

Parker, R., Larkin, T., \& Cockburn J. (2017). A visual analysis of gender bias in contemporary anatomy textbooks, Social Science and Medicine, 180(2017), 106-113. doi: 10.1016/j.socscimed.2017.03.032. 
Phillips, S.P. (2005). Defining and measuring gender: a social determinant of health whose time has come. International Journal for Equity Health, 4(11), 1-4. doi:10.1186/1475-9276-4.

Risberg, G., Johansson, E. E., Westman, G., \& Hamberg, K. (2003). Gender in medicine - an issue for women only? A survey of physician teachers' gender attitudes, International Journal for Equity in Health, 2(10), 1-8. doi: 10.1186/1475-9276-2-10.

Rollero, C. (2014). Salute in una prospettiva di genere. [Health in a gender perspective]. In N. De Piccoli (Ed.), Salute e qualità della vita nella società del benessere [Health and quality of life in the society of well-being] (217-232), Roma: Carocci.

Rollero, C., Gattino, S., \& De Piccoli, N. (2014). A gender lens on quality of life: The role of sense of community, perceived social support, self-reported health and income. Social Indicators Research, 116(3), 887-898. doi: 10.1007/s11205-013-0316-9.

Rollero, C., Glick, P., \& Tartaglia, S. (2014). Psychometric properties of short versions of the ambivalent sexism inventory and ambivalence toward men inventory. TPM: Testing, Psychometrics, Methodology in Applied Psychology, 21(2), 149-159.

Salgado, D.M., Vogt, D.S., King, L.A., King, D. W. (2002). Sex Roles, 46(7-8), 247-262. doi: 10.1023/A:1020171416038.

Verdonk, P., Benschop, Y. W. M., de Haes, H. C. J. M., \& Lagro-Janssen, T. L. M. (2008). Medical Students' Gender Awareness. Construction of the Nijmegen Gender Awareness in Medicine Scale (NGAMS). Sex Roles, 58(3-4), 222-234. doi: 10.1007/s11199-007-9326-x.

Verdonk, P., Benschop, Y. W. M., de Haes H. C. J. M., \& Lagro-Janssen T. L. M. (2009), From gender bias to gender awareness in medical education, Advances in Health Sciences Education, 14(1), 135152. doi: 10.1007/s10459-008-9100-z.

World Health Organization on Social Determinants of Health (2007). Unequal, unfair, ineffective and inefficient gender inequity in health: Why it exists and how we can change it. Final report to the WHO Commission on Social Determinants of Health, September 2007. Available online: http://www.who.int/social_determinants/resources/c sdh_media/wgekn_final_report_07.pdf.

World Health Organization, Commission on Social Determinants of Health, \& World Health Organization. (2008). Closing the Gap in a Generation. Health equity through action on the social determinants of health: Commission on Social Determinants of Health final report. Geneva: World Health Organization.

World Health Organization (2016). Women's health and well-being in Europe: beyond the mortality advantage. Copenhagen: WHO Regional Office for Europe. 